\title{
DOUBLE-POWER DOUBLE-HETEROSTRUCTURE LIGHT-EMITTING DIODES IN MICROALGAE, SPIRULINA PLATENSIS AND NANNOCHLOROPSIS OCULATA, CULTURES
}

\author{
Yean-Chang Chen \\ Department of Aquaculture and Center of Excellence for Marine Bioenvironment and Biotechnology, National Taiwan \\ Ocean University, Keelung 20248, Taiwan., ycchen@mail.ntou.edu.tw \\ Meng-Chou Lee \\ Department of Aquaculture and Center of Excellence for Marine Bioenvironment and Biotechnology, National Taiwan \\ Ocean University, Keelung 20248, Taiwan.
}

Follow this and additional works at: https://jmstt.ntou.edu.tw/journal

Part of the Marine Biology Commons

\section{Recommended Citation}

Chen, Yean-Chang and Lee, Meng-Chou (2012) "DOUBLE-POWER DOUBLE-HETEROSTRUCTURE LIGHT-EMITTING DIODES IN MICROALGAE, SPIRULINA PLATENSIS AND NANNOCHLOROPSIS OCULATA, CULTURES," Journal of Marine Science and Technology. Vol. 20: Iss. 2, Article 15.

DOI: $10.51400 / 2709-6998.1843$

Available at: https://jmstt.ntou.edu.tw/journal/vol20/iss2/15

This Research Article is brought to you for free and open access by Journal of Marine Science and Technology. It has been accepted for inclusion in Journal of Marine Science and Technology by an authorized editor of Journal of Marine Science and Technology. 


\section{DOUBLE-POWER DOUBLE-HETEROSTRUCTURE LIGHT-EMITTING DIODES IN MICROALGAE, SPIRULINA PLATENSIS AND NANNOCHLOROPSIS OCULATA, CULTURES}

\section{Acknowledgements}

This study was supported by the National Science Council (NSC100-2321-B-019-006), the Council of Agriculture (100AS-5.3.1-st-ak), Republic of China and National Taiwan Ocean University (NTOU-RDAA-2010-102022), Keelung, Taiwan 


\title{
DOUBLE-POWER DOUBLE-HETEROSTRUCTURE LIGHT-EMITTING DIODES IN MICROALGAE, SPIRULINA PLATENSIS AND NANNOCHLOROPSIS OCULATA, CULTURES
}

\author{
Yean-Chang Chen and Meng-Chou Lee
}

Key words: fluorescent lamps, natural light, Nannochloropsis oculata, Spirulina platensis, white cold DDH GaAlAs LED

\begin{abstract}
The growth conditions of two microalgae, Spirulina platensis and Nannochloropsis oculata, were tested under various light sources including white cold DDH GaAlAs LED, traditional fluorescent lamps and natural light cultures, with no difference found in the growth of biomass, indicating that white cold DDH GaAlAs LED could replace traditional fluorescent lamps, thus providing for large saving on electricity costs and preservation of cultural space. To date, the use of white cold DDH GaAlAs LEDs as light source for microalgal cultures seems to be largely unstudied.
\end{abstract}

\section{INTRODUCTION}

The effective commercial development of algae requires a cheap, durable, reliable, and highly efficient light source during culturing.

An alternative to currently-used fluorescent lamps are light-emitting diodes (LEDs) which are a semiconductor device. LEDs are light and small enough to fit into virtually any culture system, such as plant incubators and photobioreactors. They have a very long lifespan, and their high electrical efficiency minimizes heat generation. However, the light intensity of conventional LEDs is too low to be used in photobioreactors. Recently, white cold double-power doubleheterostructure (DDH) gallium aluminum arsenide (GaAlAs) chips, which can emit light with much higher intensity and efficiency than previous LEDs, have been developed. These LED arrays can emit photo fluxes as high as $900 \mu \mathrm{mol} \mathrm{m} \mathrm{m}^{-2} \mathrm{~s}^{-1}$, which is sufficient to support photosynthesis in many $\mathrm{C}_{3}$ plants

Paper sumitted 08/02/11; revised 09/02/11; accepted 09/19/11. Author for correspondence: Yean-Chang Chen (e-mail: ycchen@mail.ntou.edu.tw). Department of Aquaculture and Center of Excellence for Marine Bioenvironment and Biotechnology, National Taiwan Ocean University, Keelung 20248, Taiwan.
[1]. Therefore, LEDs represent potentially promising light sources for microalgal cultures.

It is widely recognized that microalgae can be used as feed for animals and food for humans. The nutritional value of microalgae has been substantiated by numerous studies and compares well with other conventional food products. Producing an algal biomass by photosynthesis, microalgae thus stand at the beginning of the food chain in aquatic ecosystems. The food and feed potential of the genera Spirulina and Nannochloropsis seem particularly promising. Spirulina filaments may be easily separated from their medium, are easily digestible, have a mild flavor, and are up to $70 \%$ highlyquality protein by weight [18]. Spirulina is already commercially exploited for human food supplements, fodder, and pharmaceuticals such as anti-tumor drugs [12] and anti-HIV-1 [4]. Mass cultures of Spirulina species are usually grown in open systems, such as raceway ponds and in closed photobioreactors [16]. Nannochloropsis is a marine genus of the Eustigmatophyceae [2], and is widely used as feed for fish larvae, as it contains highly nutritional compounds such as sterols [17] and polyunsaturated fatty acids [15]. Fish fry fed on this microalga grow well in part due to these fatty acids, especially $\mathrm{C} 20: 5 \omega_{3}[8]$. Previously, this alga was known as the 'marine Chlorella'; however, it contains no chlorophyll other than chlorophyll $a$ [3]. The interest in Nannochloropsis as a source of valuable pigments is not related to its capacity for single pigment accumulation, but to the availability of a range of pigments such as zeaxanthin, canthaxanthin and astaxanthin, each with high production levels [9].

The main purpose of the present study is to examine growth conditions of the microalgal cultures Spirulina platensis and Nannochloropsis oculata using white cold DDH GaAlAs LEDs as a light source in comparison with traditional fluorescent lamps and natural light.

\section{MATERIALS AND METHODS}

Spirulina platensis were cultured using Zarrouk medium, and modified Provasoli [14] enriched seawater (35\%o) was used as the culture medium for Nannochloropsis oculata. The 
microalgae were cultured in $500 \mathrm{~mL}$ flasks with $400 \mathrm{~mL}$ of culture media.

The cultures were previously cultivated and stocked in a plant incubator (Firstek RI-201, Taiwan) with $660 \mu \mathrm{mol} \mathrm{m}^{-2} \mathrm{~s}^{-1}$ light intensity, and light periods of 12:12 (Light:Dark) of fluorescent light, at $24^{\circ} \mathrm{C}$. In this study, 3 different light sources were applied to test microalgal growth: fluorescent lamp, LED with same light intensity of $660 \mu \mathrm{mol} \mathrm{m}^{-2} \mathrm{~s}^{-1}$ light intensity and natural light in a green house with varied light intensities and temperatures.

This study used white cold light DDH GaAlAs LEDs with a light efficiency of $85 \mathrm{~lm} / \mathrm{w}$. The LEDs were positioned in the incubator at a distance from the microalgal culture flasks so as to ensure light intensity of $660 \mu \mathrm{mol} \mathrm{m} \mathrm{m}^{-2} \mathrm{~s}^{-1}$. Natural light microalgal cultivations took place in a greenhouse.

The biomass of Nannochloropsis oculata was estimated using a haemacytometer (Reichert-Jung Cambridge Instruments Inc. Buffalo New York, USA) under an optical microscope (Zeiss, Primo Star) to count the cells. Due to varying length of the Spirulina platensis filaments, they could not be counted to represent its biomass. Thus its biomass was represented by applying the dry weight method to its chlorophyll contents.

The initial biomass of Nannochloropsis oculata cultures was $5 \times 10^{5}$ cells $/ \mathrm{mL}$ and the initial biomass of live Spirulina platensis cultures was equal to $20 \mathrm{mg}$ (dry weight)/L.

A spectrophotometer (Metertek SP-830, Taiwan) was used to test the biomass of the Spirulina platensis cultures. First, the absorbance of the Spirulina platensis cultural solution was manually scanned (wavelength range $600 \sim 700 \mathrm{~nm}$ ), to test for the cultures' optimum absorbed wavelength. Next, 5 concentrations (absorbance values) of $0,0.5,1.0,1.5$, and 2.0 of Spirulina platensis cultured solutions were collected using 5.0 $\mu \mathrm{m}$ of filter papers. Finally those papers were dried in a $55^{\circ} \mathrm{C}$ oven (Risen, Taiwan) for $4 \mathrm{~h}$ to determine the dry weights $(\mathrm{mg} / \mathrm{L})$ of the microalgae cultures. The regression line equation of the absorptions to dry weights of Spirulina platensis was then calculated.

The absorbance was measured every four days to estimate the biomass (growth) of the Spirulina platensis cultures. All the culture experiments were put through three replications.

\section{RESULTS}

\section{Temperatures and Light Intensities of Greenhouse (Natural Light) During Nannochloropsis oculata and Spirulina platensis Culture Experiments}

During the 32 days of culturing, light intensities in the

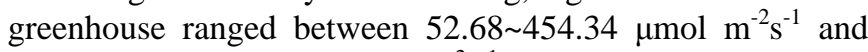
averaged $253.5 \pm 199.8 \mu \mathrm{mol} \mathrm{m}^{-2} \mathrm{~s}^{-1}$ at 9 a.m., $101.33 \sim 1650.20$ $\mu \mathrm{mol} \mathrm{m} \mathrm{m}^{-2} \mathrm{~s}^{-1}$ and $875.8 \pm 775.1 \mu \mathrm{mol} \mathrm{m} \mathrm{s}^{-2} \mathrm{~s}^{-1}$ at noon, and $65.42 \sim 1831.72 \mu \mathrm{mol} \mathrm{m}^{-2} \mathrm{~s}^{-1}$ and $947.57 \pm 879.2 \mu \mathrm{mol} \mathrm{m}^{-2} \mathrm{~s}^{-1}$ at 3 p.m.

During the experiments, the greenhouse temperature ranged from $26 \sim 34^{\circ} \mathrm{C}$ and averaged $30 \pm 4^{\circ} \mathrm{C}$ at 9 a.m.; 26

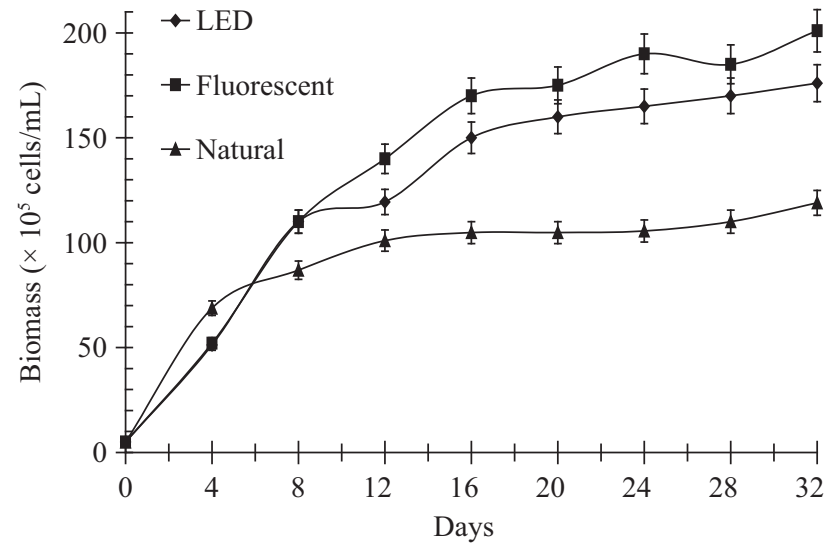

Fig. 1. Biomasses of Nannochloropsis oculata were cultured under three different light sources: white cold DDH GaAlAs LED (LED), fluorescent lamp (Fluorescent) and natural light (Natural) for 32 days.

$36.5^{\circ} \mathrm{C}$ and $31 \pm 5^{\circ} \mathrm{C}$ at noon, and $25.5 \sim 34^{\circ} \mathrm{C}$ and $29.7 \pm 4.2^{\circ} \mathrm{C}$ at 3 p.m.

\section{Effect of Various Light Sources on the Growth (Biomass) of Nannochloropsis oculata}

The microalgae were cultured under three different light sources for 32 days: white cold DDH GaAlAs LEDs, fluorescent lamps and natural light in a greenhouse. Natural light growth was faster from day 0 at day 4 , with cell numbers increased from $5 \times 10^{5} \pm 2.5 \times 10^{4}$ to $6.88 \times 10^{6} \pm 8.6 \times 10^{5}$ cells $/ \mathrm{mL}$, as opposed to $5.13 \times 10^{6} \pm 4.3 \times 10^{5}$ cells $/ \mathrm{mL}$ and $5.21 \times 10^{6} \pm 4.2 \times 10^{5}$ cells $/ \mathrm{mL}$, respectively, for the white cold DDH GaAlAs LEDs and fluorescent lamps, Fig. 1.

Although greenhouse culturing initially resulted in faster growth for Nannochloropsis oculata, by day 8, the microalgae growth of greenhouse slowed and stagnated. By day 32, total cells numbered $1.19 \times 10^{7} \pm 8.2 \times 10^{6}$ cells $/ \mathrm{mL}$, see Fig. 1 . In contrast, by day 32 incubator Nannochloropsis oculata cultures with fixed temperature and light intensity from the fluorescent lamp and white cold DDH GaAlAs LED had respectively produced $2.01 \times 10^{7} \pm 8.6 \times 10^{6}$ cells $/ \mathrm{mL}$ and $1.76 \times$ $10^{7} \pm 8.8 \times 10^{6}$ cells $/ \mathrm{mL}$. These results, Fig. 1, were tested through variance analysis, revealing that the growth (biomass) of Nannochloropsis oculata cultured under fluorescent lamps and white cold DDH GaAlAs LEDs and natural light showed no significant difference $(\mathrm{P}=0.733537>0.05 ; \mathrm{F}=0.12001<$ 4.493998).

\section{Effects of Different Light Sources on the Growth of Spirulina platensis Cultures}

Estimation of the Spirulina platensis biomass is based on the tested absorbance values of microalgae under a spectrophotometer with $680 \mathrm{~nm}$ wavelength. The absorbance values were converted to dry weight according regression line equation, Fig. 2, $\left(\mathrm{Y}=0.4794 \mathrm{X}+0.0324, \mathrm{R}^{2}=0.9879\right.$, where $\mathrm{X}$ is the value of absorbance, $\mathrm{Y}$ is the biomass $(\mathrm{mg} / \mathrm{L}))$. 


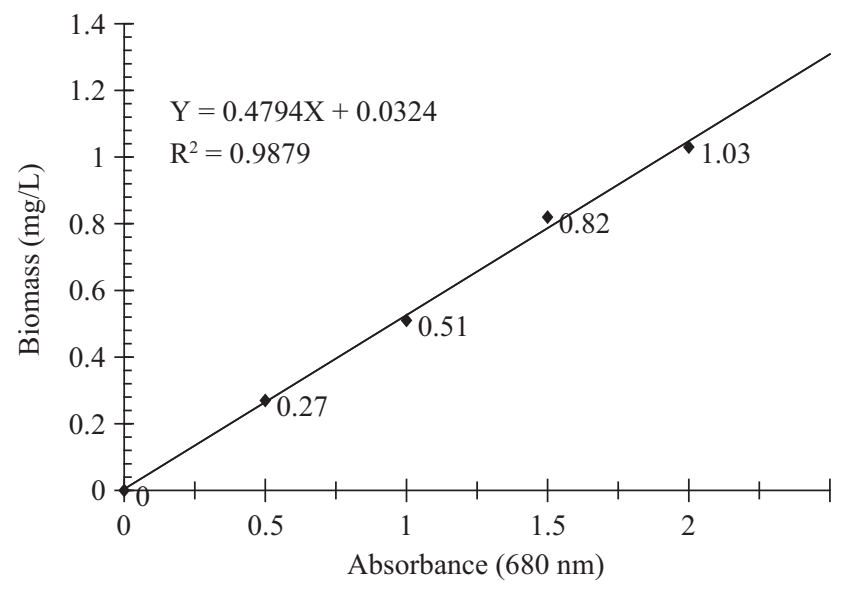

Fig. 2. Regression line $\left(Y=0.4794 X+0.0324, R^{2}=0.9879\right)$ of biomass to absorbance for estimating the growth of Spirulina platensis, in which $Y$ is biomass $(\mathrm{mg} / \mathrm{L})$ and $X$ is absorbance.

All Spirulina platensis cultures grew faster during the first $20 \mathrm{~d}$ of culturing, with the biomasses of all cultures increasing from the initial 20 to $75 \mathrm{mg} / \mathrm{L}$ on day 4 , and exceeding 300 $\mathrm{mg} / \mathrm{L}$ on day 20 . However, by day 32 , the biomasses had diverged. The average biomass of Spirulina platensis cultured in the greenhouse under natural light was $554 \pm 5 \mathrm{mg} / \mathrm{L}$, as opposed to $573 \pm 5 \mathrm{mg} / \mathrm{L}$ under with white cold DDH GaAlAs LEDs and $544 \pm 4.5 \mathrm{mg} / \mathrm{L}$ under fluorescent lamps, Fig. 3 . The statistical results reveal no significant difference of the growth (biomasses) between those cultures under the three light sources, Fig. $3,(\mathrm{P}=0.964837>0.05 ; \mathrm{F}=0.002043<$ 4.493998).

\section{DISCUSSION}

The aim of the present study is to verify whether white cold DDH GaAlAs LED could replace traditional fluorescent lamps in microalgae culturing. In our trials, the LEDs were used as a sole light source for the cultivation of microalgae, with fluorescent lamps and natural light serving as controls. Interestingly, microalgal biomass resulting from the three different light sources had no significant difference, indicating that white cold DDH GaAlAs LED can be as effective as other conventional light sources in microalgae cultivation. Though the environmental factors (e.g., temperature and light intensity) in the greenhouse were subject to variation, the biomass produced was similar to that produced by incubator cultivation with constant temperature and light intensity.

Michel and Eisentraeger [11] concluded that cultivation with LEDs was possible and could have certain advantages in microalgae culture. Katsuda et al. [4] used intermittent flashing blue light LEDs to cultivate the astaxanthin-producing green microalga, Haematococcus pluvialis, resulting in significantly higher astaxanthin production. [6-8], cultivated another fresh-water microalgae Chlorella vulgaris, under a red DDH LED similar to that used in the present study resulting



Fig. 3. Biomasses of Spirulina platensis were cultured under three different light sources: white cold DDH GaAIAs LED (LED), fluorescent lamp (Fluorescent) and natural light (Natural) for 32 days.

higher biomass, and Matthijs et al. [10] used the same light to cultivate another species microalga, Chlorella pyrenoidosa. Nedbal et al. [13] used of red light LED fluctuation effects on two green microalgae, Scenedesmus quadricauda, Chlorella vulgaris, and a blue-green microalgae Synechococcus elongates, resulting better growth than achieved with equivalent continuous light. Wang et al. [19] also concluded that Spirulina platensis achieved greatest biomass while being cultured under red light LEDs. However, the microalgal culturing periods in these studies were as short as a week. For a long-term cultivation, natural light or white light sources are suitable. The white cold LEDs applied in the present study are similar to natural light with wider spectral band for photosynthesis than that found in red and blue LEDs. The present study seems to be the first paper to use white cold GaAlAs LEDs as light source to cultivate microalgae.

The $1.5 \mathrm{~W}$ white light DDH GaAlAs LEDs used in the present study provide the same light intensity as a $20 \mathrm{~W}$ fluorescent lamp, but use 20 times less power than conventional LEDs [5]. Conventional LEDs convert $11 \%$ of electrical inputs into useful radiation and only have a 0.5 to 0.7 photosynthetically active radiation (PAR) conversion efficiency to fluorescent lamps [5]. That is, a $1.5 \mathrm{~W}$ white cold DDH GaAlAs LED is equal to a $20 \mathrm{~W}$ fluorescent and $30 \mathrm{~W}$ 
conventional LED. New GaAlAs (gallium aluminum arsenide)-based LEDs have lower voltage requirements and provide greater performance over conventional LEDs, and the development of this type of LED has led to rapid growth in commercial LED use [20].

In conclusion, using white cold DDH GaAlAs LED as a light source in microalgal cultures can result in considerable energy saving while providing biomass equal to that obtainable through the use of fluorescent and natural light sources.

\section{ACKNOWLEDGMENTS}

This study was supported by the National Science Council (NSC100-2321-B-019-006), the Council of Agriculture (100AS-5.3.1-st-ak), Republic of China and National Taiwan Ocean University (NTOU-RD-AA-2010-102022), Keelung, Taiwan.

\section{REFERENCES}

1. Ayehunie, S., Belay, A., Baba, T. W., and Ruprecht, R. M., "Inhibition of HIV-1 replication by an aqueous extract of Spirulina platensis (Arthrospira platensis)," Journal of Acquired Immune Deficciency Syndromes Human Retrovirology, Vol. 18, pp. 7-12 (1998).

2. Hibberd, D. J., "Notes of the taxonomy and momenclature of the algal classes Eustigmatophyceae and Tribophyceae (synonym Xanthophyceae)," Journal of Linnean Society of London Botany, Vol. 82, pp. 93-119 (1981).

3. Hibberd, D. J., "Eustimatophyceae," in: Margulis, L., Corlis, J., Melkonian, M., and Chapman, D. (Eds.), Handbook of Protoctista, Jones \& Bartlett Publish, Boston, pp. 30-50 (1988).

4. Katsuda, T., Shimahara, K., Shiraishi, H., Yamagami, K., Ranjbar, R., and Katoh, S., "Effect of flashing light from blue Light Emitting Diodes of cell growth and astaxanthin production of Haematococcus pluvialis,' Journal of Bioscience and Bioengineering, Vol. 102, pp. $442-446$ (2006).

5. Kubin, Š., "Radiant efficiency of Light-Emitting Diodes (LEDs)," Gartenbauwissenschaft, Vol. 59, pp. 235-238 (1994).

6. Lee, C. G. and Palsson, B., "High-density algal photobioreactors using Light-Emitting Diodes," Biotechnology and Bioengineering, Vol. 44, pp. 1161-1167 (1994).

7. Lee, C. G. and Palsson, B., "Light Emitting Diode-based algal photobioreactor with external gas exchange," Journal of Fermentation and Bioengineering, Vol. 79, pp. 257-263 (1995).

8. Lee, C. G. and Palsson, B., "Photoacclimation of Chlorella vulgaris to red light from Light-Emitting Diodes leads to autospore release following each cellular division," Biotechnology Progress, Vol. 12, pp. 249-256 (1996).

9. Lubián, L. M., Monter, O., Moreno-Garrido, I., Huertas, E., Sobrino, C., Gonzalez-Delvallw, M., and Pares, G., "Nannochloropsis (Eustigmatophyceae) as source of commercially valuable pigments," Journal of Applied Phycology, Vol. 12, pp. 249-255 (2000).

10. Matthijs, H. C. P., Balke, H., Van Hes, U. M., Kroon, B. M. A., Mur, L. R., and Binot, R. A., "Application of Light-Emitting Diodes in bioreactors: flashing light effects and energy economy in algal culture (Chlorella pyrenoidosa)," Biotechnology and Bioengineering, Vol. 50, pp. 98-107 (1996).

11. Michel, K. and Eisentraeger, A., "Light-Emitting Diodes for the illumination of algae in ecotoxicity testing," Environmental Toxicology, Vol. 19, pp. 609-613 (2004).

12. Mishima, T., Murata, J., Toyoshima, M., Fujii, H., Nakajima, M., Hayashi, T., Kato, T., and Saiki, I., "Inhibition of tumor invasion and metastasis by calcium spirulina (Ca-SP), a novel sulfated polysaccharide derived from a blue-green alga, Spirulina platensis," Clinical and Experimental Metastasis, Vol. 16, pp. 541-550 (1998).

13. Nedbal, L., Tichy, V., Xiong, F., and Grobbelaar, J. U., "Microscopic green algae and Cyanobacteria in high-frequency intermittent light," Journal of Applied Phycology, Vol. 8, pp. 325-333 (1996).

14. Provasoli, L., "Media and products for the cultivation of marine algae," in: Watanabe, A. and Hattori, A. (Eds.), Culture and Collections of Algae, Japanese Society of Plant Physiology, Tokyo, pp. 63-75 (1968).

15. Rocha, J. M., Garcia, J. E., and Henriques, M. H., "Growth aspects of the marine microalga Nannochloropsis gaditana," Biomolecular Engineering, Vol. 20, pp. 237-242 (2003).

16. Torzillo, G., Bernardini, P., and Masojídek, J., "On-line monitoring of chlorophyll fluorescence of assess the extent of photoinhibition of photosynthesis induced by high oxygen concentration and low temperature and its effect on the productivity of outdoor cultures of Spirulina platensis (Cyanobacteria)," Journal of Phycology, Vol. 34, pp. 504-510 (1998).

17. Véron, B., Dauguet, J. C., and Billard, C., "Sterolic biomarkers in marine phytoplankton. II. Free and conjugated sterols of seven species used in mariculture," Journal of Phycology, Vol. 34, pp. 273-279 (1998).

18. Vonshak, A., Abeliovich, A., Boussiba, S., Arad, S., and Richmond, A., "Production of Spirulina biomass: Effects of environmental factors and population density," Biomass, Vol. 2, pp. 175-185 (1982).

19. Wang, C. Y., Fu, C. C., and Ciu, Y. C., "Effects of using light-enutting diodes on the cultivation of Spirulina platensis," Biochemical Engineering Journal, Vol. 37, pp. 21-25 (2007).

20. Yeh, N. and Chung, J. P., "High-brightness LEDS-energy efficient lighting sources and their potential in indoor plant cultivation," Renewable and Sustainable Energy Reviews, Vol. 13, pp. 2175-2180 (2009).

21. Zittelli, G. C., Lavista, F., Bastianini, A., Rodolfi, L., Vincenzini, M., and Tredici, M. R., "Production of eicosapentaenoic acid by Nannochloropsis sp. cultures in outdoor tubular photobioreactors," Journal of Biotechnology, Vol. 70, pp. 299-312 (1999). 